Article

\title{
Prioritizing Green Spaces for Biodiversity Conservation in Beijing Based on Habitat Network Connectivity
}

\author{
Zhiyuan Lv ${ }^{1}$, Jun Yang ${ }^{1,2}$, Ben Wielstra ${ }^{3,4}$, Jie Wei ${ }^{1}$, Fei Xu ${ }^{1}$ and Yali $\mathrm{Si}^{1,5, * \mathbb{C}}$ \\ 1 Ministry of Education Key Laboratory for Earth System Modelling, Department of Earth System Science, \\ Tsinghua University, Beijing 100084, China; lvzy16@mails.tsinghua.edu.cn (Z.L.); \\ larix@tsinghua.edu.cn (J.Y.); weij16@mails.tsinghua.edu.cn (J.W.); xuf15@mails.tsinghua.edu.cn (F.X.) \\ 2 Joint Center for Global Change Studies (JCGCS), Beijing 100875, China \\ 3 Institute of Biology Leiden, Leiden University, P.O. Box 9500, 2300 RA Leiden, The Netherlands; \\ ben.wielstra@naturalis.nl \\ 4 Naturalis Biodiversity Center, P.O. Box 9517, 2300 RA Leiden, The Netherlands \\ 5 Center for Healthy Cities, Institute for China Sustainable Urbanization, Tsinghua University, \\ Beijing 100084, China \\ * Correspondence: yalisi@mail.tsinghua.edu.cn; Tel.: +86-010-62772750
}

Received: 19 February 2019; Accepted: 2 April 2019; Published: 5 April 2019

check for updates

\begin{abstract}
Rapid urbanization results in changes in land use, biogeochemical cycles, climate, hydrosystems, and biodiversity. Policy-makers have formulated ecological protection measures to facilitate sustainable development. However, traditional conservation planning mainly focuses on protecting specific green spaces, with limited consideration of the connectivity among green spaces from a habitat network perspective. Using citizen science data and occupancy modelling, we predicted habitat suitability, built habitat networks and identified key habitat patches based on their contribution to the functional connectivity of the habitat network for three focal water, forest, and open-habitat bird species. Based on the habitat requirement, small waterbodies and intermediate forest and open-habitat cover facilitate preserving water, forest and open-habitat birds. In regards to the network analysis, we found that key habitat patches with a high conservation priority were generally characterized by a relatively large patch size and/or located at critical positions in the habitat network (at central positions in the habitat network, or near large patches). We suggest that key habitat patches in restricted built-up areas are converted to protected areas or are kept as cropland under future urban planning. We emphasize the usefulness of the focal species concept in urban biodiversity conservation. Our study offers conservation recommendations from a habitat network perspective for urban planners to safeguard urban biodiversity and ecosystem health.
\end{abstract}

Keywords: forest birds; focal species; habitat suitability; open-habitat birds; occupancy model; restricted built-up areas; urban ecological planning; water birds

\section{Introduction}

The world has experienced widespread urbanization, especially since 1950, with around 55\% of the current human population living in urban areas [1]. In China, the urbanization rate was $18 \%$ in 1978 , and reached $56 \%$ by 2015 , due to the program of economic reform starting in 1978 [2]. Rapid urbanization results in changes in land use, biogeochemical cycles, climate, hydrosystems, and biodiversity, from local to regional scales [3]. Furthermore, the conversion of urban green spaces and suburban land into built-up land results in a fragmented landscape and isolated habitat patches for flora and fauna [4]. Such changes negatively affect species' survival, leading to both functional 
homogenization of bird communities [5] and a reduction of species richness in biotic communities [3,6]. This alters ecosystem structure and function, and ultimately influences ecosystem services and human well-being [7].

To both conserve urban biodiversity and achieve sustainable development, action is needed to restore the fragmented natural environment into an integrated system [8]. As space is limited in urban areas, large-scale restoration is impractical [9]. In the past, the island biogeography theory was primarily used to target areas for protection [10]. It suggests targeting bigger reserves, positioned closer to each other and approaching a circular shape, and connected by habitat corridors [11,12]. In reality, due to the constrains in cost and land use history, conservation planners can often only protect large reserves or a series of smaller ones that possess a relatively high biodiversity [13]. In this case, how critical these reserves in facilitating the overall habitat connectivity is not clear. To account for all potential habitat patches, the concept of habitat network connectivity was developed to evaluate the overall landscape conditions [8,14-16].

Habitat network connectivity reflects the functional connection among habitat patches across the landscape, so the degree to which the landscape allows or impedes the movement of organisms among habitat patches [14]. Habitat network connectivity reflects the degree of habitat availability for an organism located at any specific point on the landscape. Increased habitat network connectivity positively affects species' abundance [17], persistence and diversity [18]. The loss of a specific habitat patch might influence network connectivity in different ways [19] and crucial habitat patches could be identified based on their contribution to overall connectivity and allocated conservation priority [20].

Habitat network connectivity analysis has been used before to guide both rural and urban conservation. For example, Kang et al. [21] examined how local habitat patch area, vegetation complexity, human disturbance, and habitat connectivity influenced the diversity of forest bird communities in forest patches embedded in an urbanized landscape and confirmed the positive influence of high habitat connectivity on the survival and diversity of forest birds. Fajardo et al. [22] combined habitat suitability and connectivity analysis to reveal gaps in conservation for mammal, bird, amphibian, reptile, butterfly, and plant species in Peru. Gao et al. [23] constructed habitat networks based on habitat quality assessment by the InVEST (Integrated Valuation of Ecosystem Services and Trade-offs) model, focusing on ecosystem services for mammals, and identified important areas for conservation priority in Changzhou, China. Dondina et al. [24] proposed a method to identify an ecological network based on species specific perception of the landscape [25] and to prioritize areas for implementing or restoring corridors to enhance landscape connectivity [26].

Most urban studies simply consider green spaces to represent habitat patches for animals in general, whereas few studies actually quantify the suitability of these green spaces for specific species $[27,28]$. The main limitation in habitat suitability estimation is that observation data of target species are frequently unavailable, or collected under imperfect detection (species go undetected by the observer but actually occur there) [29]. Big citizen science data are considered a valuable resource to model species' distribution [30]. In combination with occupancy modelling, which specifically takes sampling bias into account [31], suitable habitat could be accurately mapped [30,32], providing the foundation for a habitat network. Birds are sensitive to habitat quality and are considered suitable bio-indicators for environmental quality and ecosystem health [33]. For example, water birds are often used as bio-indicators for the health of wetland ecosystems [34,35]. Furthermore, birds are easy to observe in most habitat within urban, suburban and rural landscapes.

Beijing municipality experiences rapid urbanization [36]. The Beijing Urban Master Plan (2016-2035), released in September 2017, delineates the boundary of ecological control areas (protected areas). The remaining land surface is classified as restricted built-up areas and intense built-up areas (Figure 1b). Restricted built-up areas are transition areas, which could be converted into either intense built-up areas or ecological control areas by the end of 2035. Green spaces located in areas of restricted built-up are potentially important for conserving biodiversity for conserving bird [37] diversity and that of several other taxa of vertebrates [38,39] and invertebrates [40,41]. It is vital to identify those 
green spaces that are crucial for habitat network connectivity, to prevent them from being transformed into intense built-up areas. Using Beijing as an example, this study aims to (1) construct habitat networks of three focal species considered representative for water, forest and open-habitat bird communities, based on citizen science data and occupancy modelling, and (2) prioritize habitat patches for conservation based on their contribution to habitat network connectivity.
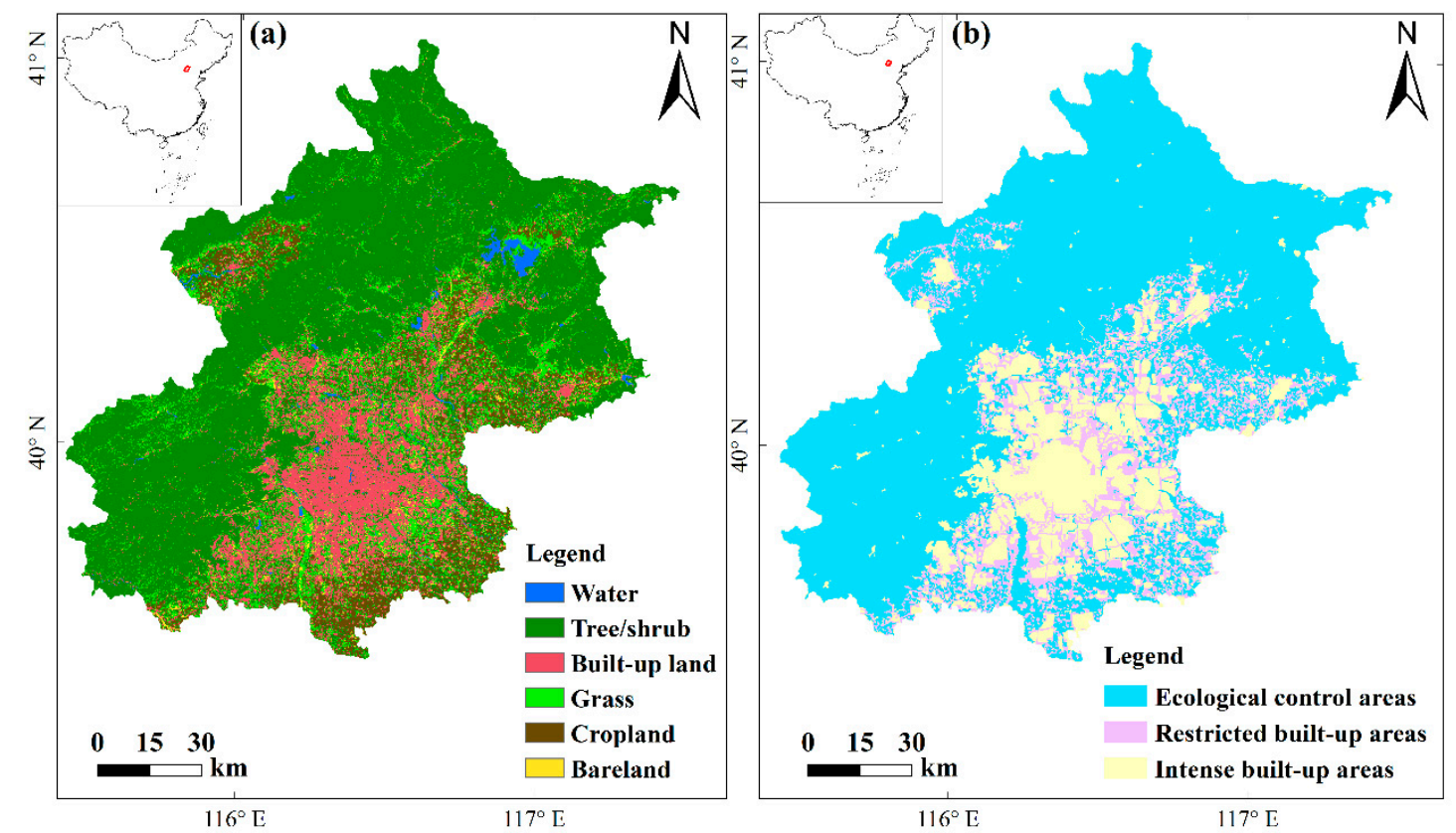

Figure 1. Map of the study area. (a) The 2015 land cover map of Beijing municipality, and (b) the layout of the ecological control areas, restricted built-up areas and intense built-up areas in the Beijing Urban Master Plan (2016-2035).

\section{Materials and Methods}

\subsection{Study Area}

Beijing is the capital of China, located in the northern part of the North China Plain $\left(39.4^{\circ}-41.6^{\circ} \mathrm{N}\right.$, $\left.115.7^{\circ}-117.4^{\circ} \mathrm{E}\right)$. Beijing municipality covers $16,808 \mathrm{~km}^{2}$ and is characterized by distinct landforms, with mountains located in the northwest and plains located in the southeast (Figure 1a). Mountainous area occupies $61.3 \%$ of the municipality and is mainly covered with shrubs and trees. The plain covers the remaining $38.7 \%$ and is the main area of urban sprawl [42]. The diverse habitat types produced by the combination of landforms support a rich flora and fauna.

\subsection{Bird Data and Focal Species Selection}

We downloaded bird observation data from the online gateway China Bird Report Center [43], which as metadata includes the species name, observation time, observation site (place name), species count and the username of the observer. We used relatively recent bird observation records for the 2008-2017 decade. We checked the location of each site based on 2015 Google Earth images and obtained the longitude and latitude of the site center following Li et al. [44].

In total, we obtained observation records for 545 bird species at 150 observation sites, including 81 resident, 179 migratory, 91 breeding, 42 wintering and 152 vagrant bird species [45,46]. We focus on resident birds (14 generalists were excluded) with observation records available throughout the year. We then categorized them into water, forest, and open-habitat bird communities, according to their main habitat requirement $[45,46]$. Water, forest, and open-habitat birds refer to groups of birds that use water, forest, or open areas (such as farmland and grassland), as their main habitat. 
The focal species concept is defined as a species or group of species for which their spatial and functional requirements encapsulate those of many other species [47]. For each of the three bird communities we chose one focal species. We used three criteria for selection: the habitat "barycenter" $B_{S}$ [48], the observation frequency (OF), and the variance of $B_{S}$ confidence intervals (VBCI). Habitat "barycenter" $B_{S}$ quantifies the habitat requirement (here referring to the habitat coverage) of a species. VBCI quantifies the variance of the habitat requirement (difference between the upper and lower limit of $95 \%$ confidence intervals of habitat coverage at each site). Species with a relatively narrow variance is more selective. Observation frequency (OF) was calculated as the number of sites in which a species was observed, divided by the total number of observation sites. It indicates the sample size of the presence data for each species.

Habitat "barycenter" $B_{S}$ is calculated by Equation (1):

$$
B_{s}=\frac{\sum n_{i} \times x_{i}}{N}
$$

where $B_{s}$ is the habitat barycenter of species $s, n_{i}$ is the number of individuals at the $i$ th observation site, $x_{i}$ is the value of environmental variables (water, forest, or open-habitat coverage) at the $i$ th observation site and $N$ is the total number of individuals recorded at all sites.

Since the median area of the observation sites is $1.2 \mathrm{~km}^{2}$, which equals the size of a $600 \mathrm{~m}$-radius buffer, we used a $600 \mathrm{~m}$-radius buffer from the center location of the observation site to calculate the habitat composition for each observation site, $B_{S}$ and VBCI. All analyses were carried out using the raster package version 2.8-19 (University of California Davis, Davis, CA, USA) [49] in the R statistical software version 3.5.0 (R Foundation for Statistical Computing, Vienna, Austria) [50].

Species with both high $B_{S}(>0.3)$ [48] and OF ( $>0.2$, equals to being observed at more than 30 sites) values were pre-selected as candidate focal species (Tables A1-A3, Appendix A). We then calculated the weighted overall score $\left(B_{S} \times 0.3+\mathrm{OF} \times 0.3+(1-\mathrm{VBCI}) \times 0.4\right)$ for these preselected species and rank them accordingly. Species with the highest overall score were selected as the focal species, namely mallard (Anas platyrhynchos), grey-headed woodpecker (Picus canus), and Eurasian collared dove (Streptopelia decaocto), as the focal species for water, forest, and open-habitat bird communities.

\subsection{Environmental Variables}

Environmental variables used to predict the habitat suitability for focal water, forest, and open-habitat bird species are summarized in Table 1. Six site-level environmental variables that are ecologically related to habitat suitability were used to predict the occupancy probability. Three observation-level environmental variables were used to quantify observation bias.

Table 1. Site-level and observation-level environmental variables used in the occupancy model to predict bird habitat suitability in Beijing municipality.

\begin{tabular}{cccc}
\hline & Variables & Data Source & Data Resolution \\
\hline \multirow{2}{*}{ Site-level } & $\begin{array}{c}\text { Percentage of land cover types \& } \\
\text { distance to the nearest water body } \\
\text { (Dis2water) }\end{array}$ & 2015 land cover map [51] & $30 \mathrm{~m}$ \\
\cline { 2 - 4 } & Elevation (Elev) & $\begin{array}{c}\text { Advanced Spaceborne Thermal Emission } \\
\text { and Reflection Radiometer Global Digital } \\
\text { Elevation Model (ASTER GDEM) data [52] }\end{array}$ & $30 \mathrm{~m}$ \\
\cline { 2 - 4 } & $\begin{array}{c}\text { Distance to the nearest major road } \\
\text { (Dis2road) }\end{array}$ & Vector data of major roads [53] & $30 \mathrm{~m}$ \\
\cline { 2 - 4 } & Nightlight index (Light) & $\begin{array}{c}\text { Operational Linescan System (OLS) by the } \\
\text { U.S. Air Force Defense Meteorological } \\
\text { Satellite Program (DMSP) [54] }\end{array}$ & $1 \mathrm{~km}$ \\
\hline
\end{tabular}


Table 1. Cont.

\begin{tabular}{|c|c|c|c|}
\hline & Variables & Data Source & Data Resolution \\
\hline \multirow{3}{*}{$\begin{array}{l}\text { Observation- } \\
\text { level }\end{array}$} & Date & $\begin{array}{l}\text { 2008-2017 Bird observation data from } \\
\text { China Bird Report Center [43] }\end{array}$ & daily \\
\hline & Land surface temperature & $\begin{array}{l}\text { Land Surface Temperature/Emissivity } \\
\text { Monthly L3 Global 0.05Deg CMG (the } \\
\text { NASA Land Processes Distributed Active } \\
\text { Archive Center [55]) }\end{array}$ & 0.05 degree \\
\hline & Precipitation & $\begin{array}{c}\text { European Centre for Medium-Range } \\
\text { Weather Forecasts (ECMWF) ERA-Interim, } \\
\text { Monthly means of Daily Forecast } \\
\text { Accumulations [56] }\end{array}$ & 0.75 degree \\
\hline
\end{tabular}

Land-use composition determines the availability of food and roosting areas [21,57]. We used the best available land cover map, produced in 2015 and with an overall classification accuracy of $88 \%$ [51]. Land cover types include water, built-up land, bareland, tree/shrub (forest), grass and cropland. Bareland refers to areas that vegetation is hardly observable but dominated by exposed soil, sand, gravel, and rock backgrounds. We then calculated the percentage of land cover type within a buffer of $600 \mathrm{~m}$ around the observation location to extract habitat composition using FRAGSTATS software Version 4 (University of Massachusetts, Amherst, USA) [58].

Additionally, the distance to the nearest water body indicates the accessibility to water resources, another important factor for bird habitat selection [59,60]. Distance to road positively affects bird species richness [61] and traffic volume on roads positively correlated with woodland bird mortality [62]. We then adopted distance to the nearest major road and nightlight index as proxies of human disturbance $[61,63,64]$. Considering multi-collinearity problems among variables, we kept one variable if two were correlated (a Pearson correlation coefficient $>0.5$ [65]) and retained the one that was more relevant to bird presence based on expert knowledge. As time of year (date), temperature and precipitation during observations influence detection probability [31], we extracted monthly average temperature and monthly total precipitation for each observation site for the period 2008-2017. All the calculations were conducted in ArcGIS software Version 10.3.1 (ESRI Inc., Redlands, CA, USA) [66].

\subsection{Habitat Suitability Modelling}

Citizen science data are often collected without a standardized field protocol and explicit sampling design [30]. To cope with potential sampling bias, we used occupancy modelling, which takes imperfect detection of species into account and separates detection processes and species' occupancy in a hierarchical way $[30,31]$. If a species was recorded in a specific month, the detection record was assigned a value of 1 for that month and if not it was assigned a value of 0 . In addition, a site not visited at a specific month was considered as a "missing observation". The probability for the observed detection history $(0 / 1)$ of a species at a specific site $P_{\text {observed }}$ is the combination of the occupancy probability $\psi$ and the detection probability ( $p$, Equation (2)):

$$
P_{\text {observed }}(0 / 1)=\text { Occupancy }(\psi) \times \text { Detectability }(p)
$$

where $\psi$ and $p$ are functions of site-level and observation-level variables, respectively (Equations (3) and (4)).

$$
\begin{aligned}
& \operatorname{Logit}\left(\psi_{i}\right)=A_{0}+A_{1} x_{i 1}+A_{2} x_{i 2}+\cdots+A_{n} x_{i n} \\
& \operatorname{Logit}\left(p_{i j}\right)=B_{0}+B_{1} y_{j 1}+B_{2} y_{j 2}+\cdots+B_{n} y_{j n}
\end{aligned}
$$

where $x_{i 1} \ldots x_{i n}$ are site-level variables (Table 1 ) for site $i$, and $y_{j 1} \ldots y_{j n}$ are observation-level variables (Table 1) for survey $j$.

We built occupancy models for the three focal water, forest and open-habitat bird species using the R package Unmarked version 0.12.3 (North Carolina State University, Raleigh, NC, USA) [67] in 
the R statistical software version 3.5.0 (R Foundation for Statistical Computing, Vienna, Austria) [50]. We performed model selection on both occupancy and detection probability submodels simultaneously using the R package MuMIn version 1.42.1 (Institute of Nature Conservation Polish Academy of Sciences, Krakow, Poland) [68] in the R statistical software version 3.5.0 (R Foundation for Statistical Computing, Vienna, Austria) [50]. We used Akaike's Information Criterion adjusted for small sample size (AIC $c$ ) to rank the models $(\triangle \mathrm{AIC} c<2)[69]$. We examined the goodness of fit of selected models using a chi-square $\left(\chi^{2}\right)$ test with 1000 bootstraps replicates and excluded models with a $p$-value larger than 0.05 [70]. Considering some top models might have a lower Akaike weight, we adopted a model-averaging approach [69] by starting with the model with the highest Akaike weight and including the model with the second highest weight until $\sum w_{m}=0.95$. Then the coefficient of each variable in the final model was estimated by the weighted mean of the selected models (according to the Akaike weight of the model) [71]. The response curve of the most important environmental factors for each focal species was generated by plotting the response value (and the $95 \%$ confidence intervals) at the range of the variable of interest, based on the prediction of the final occupancy submodel.

To define suitable and unsuitable area based on the predicted occupancy probability $(0-1)$, we used the sample frequency instead of an arbitrary number as a threshold [72]. Sample frequency was calculated as the proportion of species' occurrences across all sites [72]. Hence, areas with an occupancy probability above $0.55,0.57$, and 0.79 were defined as suitable habitat to build the habitat network for water, forest and open-habitat focal bird species. Generating habitat suitability maps and extracting suitable habitat patches were conducted in ArcGIS software [66].

\subsection{Habitat Network Connectivity Analysis}

The suitable habitat patches, as stepping-stone nodes, are crucial connections to maintain habitat network connectivity. We employed the probability of connectivity (PC), which is considered a robust metric to evaluate the functional connectivity of a habitat network $[15,20]$. If there is a set of habitat patches and connections among them, PC is defined as the probability that two animals are randomly placed within the landscape and fall into habitat areas that are mutually reachable [15], and is calculated with Equation (5):

$$
P C=\frac{\sum_{i=1}^{n} \sum_{j=1}^{n} a_{i} a_{j} p_{i j}^{*}}{A_{L}^{2}}
$$

where $n$ is the total number of habitat patches, $a_{i}$ and $a_{j}$ represent the area of suitable habitat patch $i$ and $j, p_{i j}^{*}$ is the maximum product probability of all the possible paths between patches $i$ and $j$, and $A_{L}$ stands for the total study area.

We quantified the importance of patches by removing each single patch from the network to determine the change in network connectivity $[15,20]$. The importance of each patch is assessed by the absolute difference in the probability connectivity $(d P C)$ before and after the removal, and is calculated as a percentage from Equation (6):

$$
d P C_{k}(\%)=\frac{P C-P C_{\text {remove }, k}}{P C} \times 100
$$

where $P C_{k}$ is the overall connectivity value when all existing patches are present in the landscape and $P C_{\text {remove }, k}$ is the connectivity value after the removal of a specific patch $k$. A patch with a greater $d P C$ has a higher contribution to the network connectivity.

Different bird species vary in their dispersal abilities. Hence, we performed connectivity analysis over a range of dispersal distances from $1-50 \mathrm{~km}(1,3,5,10,20,30,40,50 \mathrm{~km})$, and adopted the mean of the eight $\mathrm{dPC}$ values to make the results applicable to birds with different dispersal distances. The habitat network connectivity analyses were performed using the Conefor Inputs extension in ArcGIS software [66] and Conefor Sensinode software Version 2.2 (University of Lleida, Lleida, Spain) [73]. Based on their contribution to habitat network connectivity (dPC), we classified 
habitat patches into five levels of conservation priority (very high, high, medium, low, and very low) using the natural break (Jenks) method [74] in ArcGIS (grouping similar dPC values into one class and maximizing differences between classes). Patches assigned with a high or very high level of conservation priority were defined as key habitat patches. We then identified whether key patches are protected or not, or whether they fall into the restricted build-up areas, based on the boundary of the ecological control area outlined in the Beijing Urban Master Plan (Figure 1b).

\section{Results}

\subsection{Habitat Suitability for Focal Species}

The final models for the three focal species are shown in Table 2. Mean detection probability of the mallard (water bird) was the highest (0.56), followed by the grey-headed woodpecker (forest bird) (0.40), and then the Eurasian collared dove (open habitat bird) (0.20).

Table 2. Final models for estimating the occupancy $(\psi)$ and detection $(p)$ probability for focal water bird mallard, forest bird grey-headed woodpecker and open-habitat bird Eurasian collared dove in Beijing.

\begin{tabular}{|c|c|}
\hline Birds & Models \\
\hline Water & $\psi($ water + bareland + grass + dis 2 water + dis 2 road $) p($ date + temperature + precipitation $)$ \\
\hline Forest & $\psi($ water + bareland + forest + grass + cropland $) p($ date + temperature + precipitation $)$ \\
\hline Open-habitat & $\psi($ water + bareland + forest + grass $/$ cropland + dis 2 water $) p($ date + temperature + precipitation $)$ \\
\hline
\end{tabular}

For mallard, the percentages of water and grass were positively correlated with occupancy probability (Table 3). The most important variable was water and mallard only required relatively low coverage of water (Figure 2a). Suitable habitats for water birds mainly appeared around reservoirs, wetlands, lakes, and rivers (Figure 3a), such as Miyun reservoir in Northeast Beijing, Guanting reservoir and Wild Duck Lake national wetland park in the northwest, as well as wetlands and green spaces along the Chaobai and Wenyu rivers in urban areas (Figure 3a).

Table 3. The coefficient, standard error and $p$-value of each variable in the occupancy submodels for the water bird mallard, the forest bird grey-headed woodpecker and the open-habitat bird Eurasian collared dove in Beijing.

\begin{tabular}{cccccccccc}
\hline Birds & Models & Intercept & Water & Bareland & Forest & Grass & Cropland & Dis2water & Dis2road \\
\hline \multirow{2}{*}{ Water } & Coefficient & 11.63 & 31.39 & 0.81 & - & 0.81 & - & -0.82 \\
& SE & 5.19 & 13.56 & 0.57 & - & 0.36 & - & 0.65 & 0.34 \\
& $p$-value & 0.03 & 0.02 & 0.15 & - & 0.02 & - & 0.21 & 0.46 \\
\hline \multirow{2}{*}{ Forest } & Coefficient & 2.68 & 0.07 & -0.40 & 3.89 & 0.05 & -0.21 & - & - \\
& SE & 0.88 & 0.29 & 0.61 & 1.09 & 0.32 & 0.42 & - & - \\
\hline \multirow{2}{*}{ Open } & -value & 0.00 & 0.81 & 0.52 & 0.00 & 0.89 & 0.62 & - \\
habitat & Coefficient & -0.09 & 0.22 & -2.52 & -0.36 & & $4.13 *$ & -1.37 & - \\
& SE & 0.59 & 0.34 & 1.42 & 0.48 & & $1.55^{*}$ & 0.84 & - \\
\hline
\end{tabular}

Notes: Water, bareland, forest, grass, and cropland: the percentage of each land cover type within a $600 \mathrm{~m}$-buffer. Dis2water: distance to the nearest water body; Dis2road: distance to the nearest major road; ${ }^{*}$ : grass and cropland are grouped into one type.

For grey-headed woodpecker, the percentage of forest positively influenced occupancy probability and was also the most important variable (Table 3). The occurrence probability of this species sharply increased when the forest cover reached 30\% (Figure $2 b$ ). Highly suitable areas were concentrated in the northern and southwestern suburban mountain forest and forest in urban green spaces (Figure $3 b$ ). 
For Eurasian collared dove, the percentage of open habitat (grass and cropland) positively influence occupancy probability (Table 3). The probability of presence increased considerably when the cover of grass and cropland reached 25\% (Figure 2c). Suitable habitats for open habitat birds were mainly positioned in Eastern and Southern Beijing in the Fangshan, Daxing, Tongzhou, Shunyi, Pinggu, and Yanqing districts (Figure 3c).
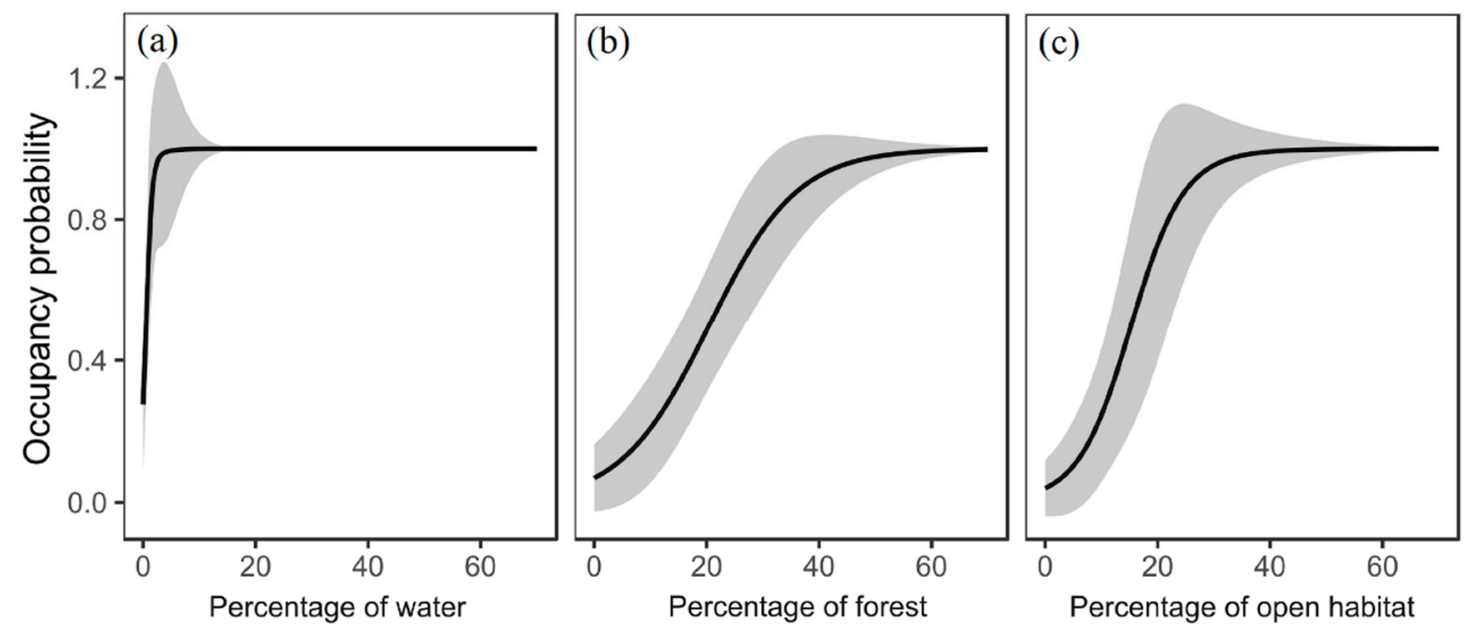

Figure 2. Response curves illustrating the relationship between the environmental factors (only the most important variables were presented) and the occupancy probability of the water bird mallard (a), the forest bird grey-headed woodpecker (b), and the open-habitat bird Eurasian collared dove (c). Open habitat refers to grassland and cropland. The grey areas indicate the $95 \%$ confidence interval.

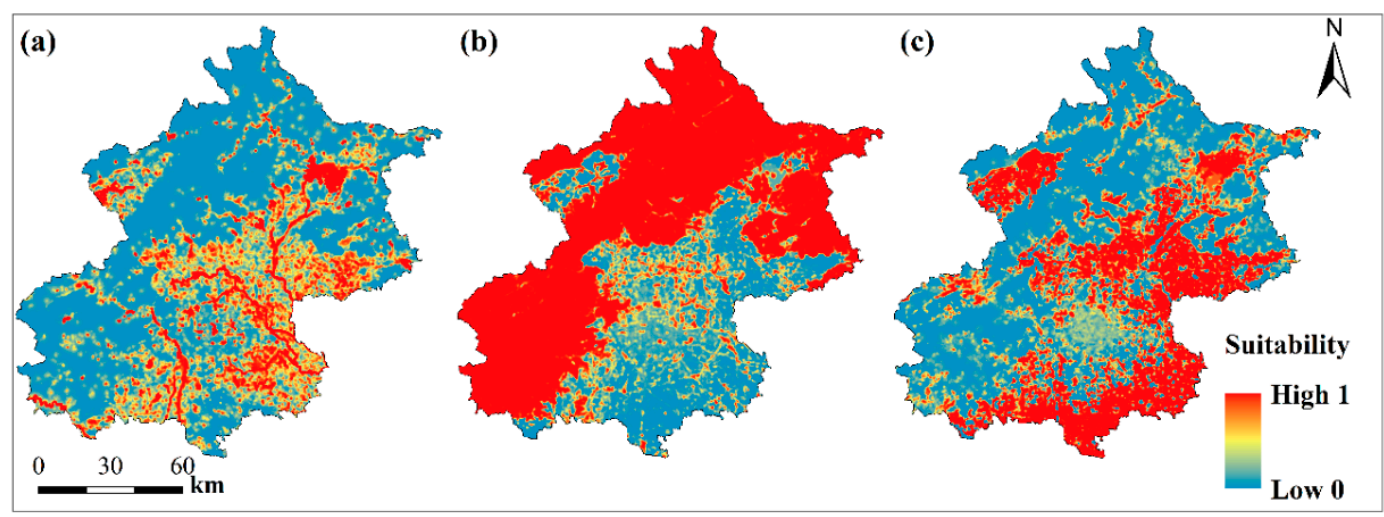

Figure 3. The habitat suitability map for water bird mallard (a), forest bird grey-headed woodpecker (b), and open-habitat bird Eurasian collared dove (c) in Beijing municipality.

\subsection{The Habitat Network Connectivity and Conservation Priority}

For the focal water bird species, key habitat patches were mainly distributed in east and central Beijing (the Chaobai river in Shunyi district, the Liangshui and Xiaotaihou rivers in Tongzhou district, the Wenyu and Ba rivers in Chaoyang district, Miyun reservoir in Miyun district, the North Canal and Yunchaojian rivers in Tongzhou district, the Ju and Ru rivers in Pinggu district, the Sha and Wenyu rivers in Changping district, the Qing river in Haidian district and Olympic Park in Chaoayng district) (Figure 4a, Table A4, Appendix A). For the focal forest bird species, key patches are found in north and southwest Beijing (Yanqing, Huairou, Miyun, Fangshan, Shijingshan, and Mentougou districts), and central Beijing (the Wenyu river in Shunyi and Chaoyang districts, and the Chaobai river in Shunyi district) (Figure 4b, Table A4, Appendix A). For the focal open-habitat bird species, most of key patches are located in northeast and southeast Beijing (Daxing, Tongzhou, Shunyi, and Yanqing districts) (Figure 4c, Table A4, Appendix A). 


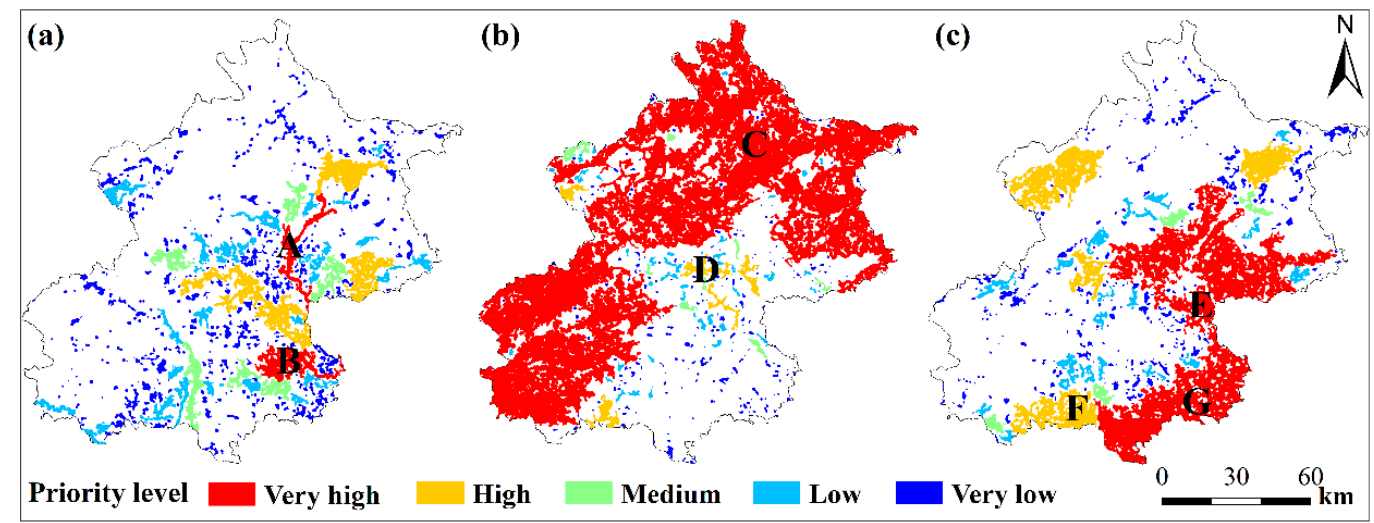

Figure 4. Rank of habitat patches with conservation priority based on their contribution to the habitat network connectivity for the water bird mallard (a), the forest bird grey-headed woodpecker (b), and the open-habitat bird Eurasian collared dove (c) in Beijing municipality. White area represents unsuitable habitat. A: Chaobai river in Shunyi district; B: Liangshui and Xiaotaihou rivers in Tongzhou district; C: forest in Yanqing, Huairou and Miyun districts; D: Wenyu river in Shunyi district; E: grass and cropland in Tong zhou, Chaoyang and Shunyi districts; F: grass and cropland in Fangshan district; G: grass and cropland in Daxing and Tongzhou districts.

Most of the key habitat patches for forest birds (92\%) were located in ecological control areas, whereas a small percentage fell into restricted built-up areas (Figure 5). For water and open-area birds, only $37 \%$ and $52 \%$ of key habitat patches were in ecological control areas (Figure 5). Key habitat patches for water birds in restricted built-up areas, with a total surface area of $321.3 \mathrm{~km}^{2}$, were mainly distributed in Northeast Beijing (along the Chaobai, Ru, and Ju rivers), Central Beijing (surroundings of Shahe reservoir and the Wenyu river), and Southwest Beijing (along the Liangshui river in Yizhuang). For forest birds, only $272.9 \mathrm{~km}^{2}$ of key habitat patches were located in restricted built-up areas, and mainly located at the foot of the mountains and in the Xiaotangshan modern agricultural park in Changping district. A total of $1036.5 \mathrm{~km}^{2}$ of key habitat patches for open-habitat birds occurred in restricted built-up areas, and were mainly distributed in the Daxing, Tongzhou, and Shunyi districts.

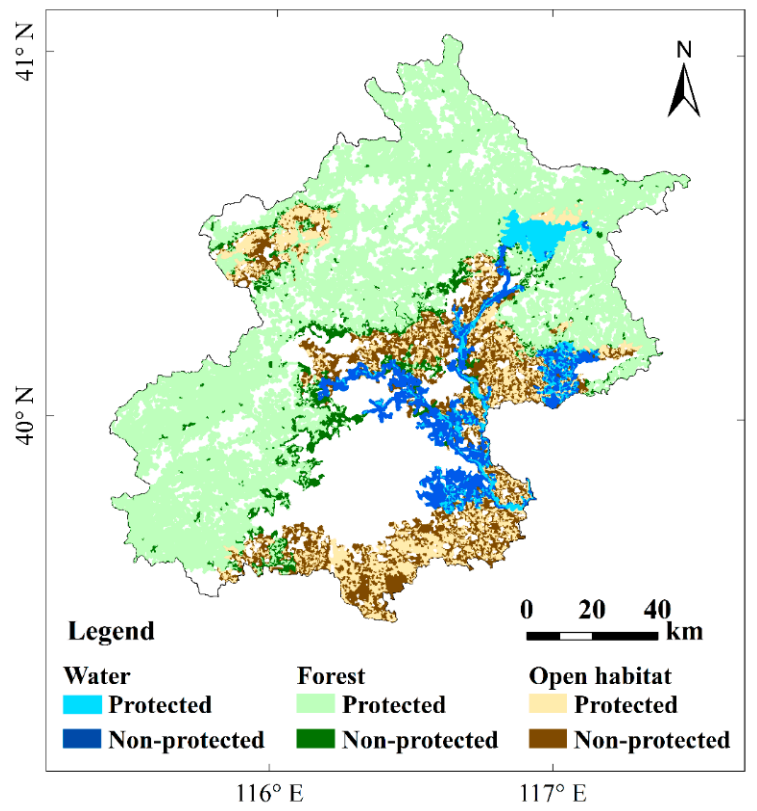

Figure 5. The distribution of key habitat patches with high conservation priority (high or very high levels) inside (protected) and outside (non-protected) of the current ecological control areas for focal water, forest, and open-habitat bird species in Beijing municipality. 


\section{Discussion}

Our study proposes an approach in prioritizing urban green space protection from a focal species habitat network perspective. Using occupancy modelling and citizen science bird observation data, we predicted habitat suitability for three focal water, forest, and open-habitat bird species, presumed to encapsulate the needs of wider species communities. Since different communities show distinct habitat preference, our approach could more accurately quantify habitat patches for targeting communities, compared to simply using green space to delineate the habitat in general. The identified core habitat patches in the habitat networks could guide urban green space management and provide the scientific basis for urban planners to target areas for protection priority in the future development plan. By using focal species of three bird communities as bio-indicators, our study provides evidence-based measures to help maintain urban habitat connectivity and preserve biodiversity.

The quantified habitat requirements, suitable habitat maps and identified core habitat patches for the focal water, forest and open-habitat bird species could guide green space management and urban planning. The focal water bird mallard requires only a relatively low surface area of water, suggesting maintaining or restoring small waterbodies in urban green areas would be an efficient way of maintaining water birds. An alternative explanation would be that most waterbodies in urban areas are relatively small and water birds have adapted to this kind of landscape. On the other hand, frost birds and open-habitat birds need a moderate level of forest and open-habitat cover to survive. This implies that the composition of forest and open-habitat should be taken into account when designing city parks, restoring habitats or setting up conservation plans.

We found that large habitat patches are important in facilitating habitat network connectivity. For example, patch ' $\mathrm{B}$ ', ' $\mathrm{C}$ ', and ' $\mathrm{G}$ ' (Figure 4) are the largest patches in the habitat network of the focal species and are also some of the most important patches in facilitating habitat connectivity. Patch ' $\mathrm{B}$ ' is located in an area composed of rivers (e.g., the Liangshui and Xiaotaihou rivers), wetlands, parks and grassland. Patch ' $C$ ' is covered by continuous forest and ' $G$ ' is grass/farmland. Larger patch size contributes to a greater intra-patch and inter-patch connectivity in a habitat network [16,19]. They not only offer a larger area of habitat, but also increase the amount of area-weighted dispersal flux [19] and, hence, should to be protected.

In addition to the size of patches, we found that habitat patches positioned at a critical spatial position in the habitat network are also important for maintaining habitat connectivity. By acting as stepping-stones, patches located in the center of the network and/or near large patches, tend to have a higher contribution to the habitat connectivity. For example, for the representative water bird species, patch 'A' (Figure 4a) along the Chaobai River connects surrounding habitat patches. For the representative forest bird species, patch ' $\mathrm{D}$ ' (Figure $4 \mathrm{~b}$ ) along the Wenyu River, acted as a key stepping stone connecting the urban and suburban areas. For the focal open-habitat bird species, patch ' $E$ ' (Figure 4c) connects the northern and southern key patches. Moreover, patches near large patches (e.g., patch ' $\mathrm{F}$ ' in Figure 4c) not only facilitates species dispersal, but also acts as a barrier against human disturbance [16]. Loss of such key stepping-stone patches might rapidly reduce the overall connectivity and increase the chance of network collapse $[75,76]$. It is, therefore, important to evaluate sites for conservation priority from a network perspective, instead of only at the site level. Hence, such stepping-stone patches should be prioritized in urban biodiversity conservation [16,37].

We suggest conservation planning takes into account both habitat suitability and habitat network connectivity. As the designation for restricted built-up areas in Beijing is not yet fixed, we suggest that the identified key habitat patches within restricted built-up areas for water and forest birds should be converted into ecological control areas and those for open-habitat communities should be preserved as cropland under future urban planning (Table A4, Appendix A).

We selected focal water, forest and open-habitat birds with distinct habitat preferences. The spatial and functional requirement of these focal species could help define the environmental limits and help protect other species [33]. A rigid selection procedure is critical, given that focal species need to reflect the overall biodiversity of the territory under investigation. Besides the commonly used criteria habitat 
barycenter $[33,48]$, we also considered the variance of the habitat barycenter. Smaller variance indicates that the species is more selective toward one specific habitat type and uses alternative habitats less. In consequence, by protecting the habitat of selected focal species, other taxonomic groups could also be protected, including those with less observation data available. We underline the usefulness of applying the focal species concept in urban biodiversity conservation.

Our study highlights the combination of occupancy modelling of focal species with network connectivity analysis to identify key habitat patches for conservation prioritization. Species distribution modelling (SDM) has been frequently used to quantify environment-species relationships and generate suitability habitat maps [77] to guide urban wildlife protection and biodiversity conservation (e.g., $[32,78]$ ). The habitat network connectivity has hardly been investigated after suitable habitat has been delineated using SDM (except for [22,48,79]). In real world conservation, not all suitable habitat can be protected, especially under ongoing urbanization. The quantification of the core habitat patches from a habitat network connectivity perspective offers an efficient way to target the most important areas for protection priority. In addition, we built the occupancy model based on 10-year bird observation data and the 2015 land cover map, mainly due to the limited number of bird records. We recommend promoting the collection of citizen science data, as more observations and observation sites would improve the prediction of suitable habitat patches. Nevertheless, our approach of coupling focal specie occupancy modelling with network analysis to guide conservation efforts could be applied to other cities, where fine resolution land cover map and bird observation data are available.

\section{Conclusions}

Since habitat fragmentation causes biodiversity loss, it is necessary to protect urban biodiversity based on habitat suitability and the functional connectivity of the habitat network. We select three focal species presuming their habitat requirements encapsulate many other species and underline their usefulness in urban biodiversity conservation. Based on the habitat requirement, small waterbodies and intermediate forest and open-habitat cover facilitate preserving water, forest, and open-habitat bird communities, respectively. In light of the network analysis, key habitat patches with a high conservation priority are generally characterized by having a large surface area and/or being located at critical positions in the habitat network (i.e., at central positions in the habitat network and/or near large patches). We suggest that urban planners preserve such key patches in restricted built-up areas (Table A4, Appendix A) in future urban development plans. We consider that the evaluation of individual habitat patches in terms of conservation priority, based on the contribution of these patches to habitat network connectivity, is an effective method to optimize decision-making in future urban conservation planning. Our findings provide guidelines for the conservation of local biodiversity and sustainable urban development.

Author Contributions: Conceptualization: Y.S.; methodology: Y.S., J.Y., Z.L., and B.W.; formal analysis: Z.L., and J.W.; writing —original draft preparation: Z.L. and Y.S.; writing—review and editing: all authors.

Funding: This research was partially supported by the National Research Program of the Ministry of Science and Technology of the People's Republic of China (No. 2017YFA0604404 and 2016YFA0600104), the National Natural Science Foundation of China (41471347), and donations from Delos Living LLC and the Cyrus Tang Foundation to Tsinghua University.

Acknowledgments: We thank Wenyuan Zhang and Wenzhao Wu for assistance in bird data processing and Yanjie $\mathrm{Xu}$ for discussion. We thank two anonymous reviewers for their valuable comments.

Conflicts of Interest: The authors declare no conflict of interest. 


\section{Appendix A}

Table A1. Summary of 14 studied resident water bird species observed from 2008-2017 in Beijing municipality. $B_{s}$ : the weighted mean of water coverage at all site of presence; OF: observation frequency calculated as the number of sites in which a species was observed, divided by the total number of observation sites; LCI: lower limit of $95 \%$ confidence interval for the water coverage at all site of presence; UCL: upper limit of 95\% Confidence Interval for the water coverage at all site of presence;

VBCI: variance the water coverage at all site of presence (UCL - LCL). Species with both high $B_{S}(>0.3)$ and OF ( $\left.>0.2\right)$ values are pre-selected candidate focal species (Id 1-3). Score is calculated as $B_{S} \times 0.3+\mathrm{OF} \times 0.3+(1-\mathrm{VBCI}) \times 0.4$. Species with the highest score were selected as the focal species.

\begin{tabular}{|c|c|c|c|c|c|c|c|c|}
\hline Id & English Name & Scientific Name & $B_{s}$ & OF & LCI & UCI & VBCI & Score \\
\hline 1 & Mallard & Anas platyrhynchos & 0.313 & 0.453 & 0.073 & 0.183 & 0.111 & 0.586 \\
\hline 2 & Little Grebe & Tachybaptus ruficollis & 0.317 & 0.373 & 0.082 & 0.214 & 0.132 & 0.555 \\
\hline 3 & Eastern spot-billed Duck & Anas zonorhyncha & 0.354 & 0.213 & 0.114 & 0.326 & 0.212 & 0.485 \\
\hline 4 & Black-crowned Night Heron & Nycticorax nycticorax & 0.278 & 0.340 & 0.055 & 0.186 & 0.132 & 0.533 \\
\hline 5 & White wagtail & Motacilla alba & 0.214 & 0.367 & 0.054 & 0.187 & 0.133 & 0.521 \\
\hline 6 & Eurasian teal & Anas crecca & 0.538 & 0.173 & 0.101 & 0.358 & 0.257 & 0.510 \\
\hline 7 & Ruddy shelduck & Tadorna ferruginea & 0.517 & 0.167 & 0.106 & 0.372 & 0.265 & 0.499 \\
\hline 8 & Common kingfisher & Alcedo atthis & 0.139 & 0.333 & 0.051 & 0.192 & 0.140 & 0.485 \\
\hline 9 & Grey heron & Ardea cinerea & 0.240 & 0.240 & 0.066 & 0.262 & 0.196 & 0.465 \\
\hline 10 & Mandarin duck & Aix galericulata & 0.142 & 0.213 & 0.077 & 0.288 & 0.211 & 0.422 \\
\hline 11 & Ibisbill & Ibidorhyncha struthersii & 0.019 & 0.047 & 0.009 & 0.036 & 0.027 & 0.409 \\
\hline 12 & Brown dipper & Cinclus pallasii & 0.020 & 0.040 & 0.007 & 0.034 & 0.026 & 0.407 \\
\hline 13 & Crested kingfisher & Megaceryle lugubris & 0.152 & 0.173 & 0.040 & 0.268 & 0.228 & 0.406 \\
\hline 14 & Plumbeous water redstart & Rhyacornis fuliginosa & 0.051 & 0.073 & -0.065 & 0.283 & 0.348 & 0.298 \\
\hline
\end{tabular}


Table A2. Summary of 35 studied resident forest bird species observed from 2008-2017 in Beijing municipality. $B_{S}$ : the weighted mean of forest coverage at all site of presence; OF: observation frequency calculated as the number of sites in which a species was observed, divided by the total number of observation sites; LCI: lower limit of $95 \%$ confidence interval for the forest coverage at all site of presence; UCL: upper limit of 95\% Confidence Interval for the forest coverage at all site of presence; VBCI: variance the forest coverage at all site of presence (UCL - LCL). Species with both high $B_{S}(>0.3)$ and OF ( $\left.>0.2\right)$ values are pre-selected candidate focal species (Id 1-16). Score is calculated as $B_{S} \times 0.3+\mathrm{OF} \times 0.3+(1-\mathrm{VBCI}) \times 0.4$. Species with the highest score were selected as the focal species.

\begin{tabular}{|c|c|c|c|c|c|c|c|c|}
\hline Id & English Name & Scientific Name & $B_{s}$ & OF & LCI & UCI & VBCI & Score \\
\hline 1 & Grey-headed woodpecker & Picus canus & 0.554 & 0.433 & 0.389 & 0.518 & 0.130 & 0.644 \\
\hline 2 & Great tit & Parus major & 0.575 & 0.440 & 0.419 & 0.576 & 0.157 & 0.642 \\
\hline 3 & Great spotted woodpecker & Dendrocopos major & 0.400 & 0.553 & 0.327 & 0.454 & 0.127 & 0.635 \\
\hline 4 & Light-vented bulbul & Pycnonotus sinensis & 0.399 & 0.547 & 0.301 & 0.428 & 0.127 & 0.633 \\
\hline 5 & Grey-capped greenfinch & Chloris sinica & 0.526 & 0.407 & 0.356 & 0.512 & 0.155 & 0.618 \\
\hline 6 & Marsh tit & Poecile palustris & 0.490 & 0.420 & 0.354 & 0.508 & 0.154 & 0.611 \\
\hline 7 & Plain laughingthrush & Garrulax davidi & 0.706 & 0.253 & 0.492 & 0.709 & 0.217 & 0.601 \\
\hline 8 & Vinous-throated parrotbill & Sinosuthora webbiana & 0.529 & 0.360 & 0.430 & 0.603 & 0.174 & 0.597 \\
\hline 9 & Red-billed blue magpie & Urocissa erythroryncha & 0.578 & 0.320 & 0.430 & 0.620 & 0.190 & 0.593 \\
\hline 10 & Meadow bunting & Emberiza cioides & 0.615 & 0.260 & 0.471 & 0.674 & 0.203 & 0.581 \\
\hline 11 & Godlewski's bunting & Emberiza godlewskii & 0.703 & 0.227 & 0.517 & 0.763 & 0.245 & 0.581 \\
\hline 12 & Yellow-bellied tit & Pardaliparus venustulus & 0.595 & 0.280 & 0.360 & 0.572 & 0.212 & 0.578 \\
\hline 13 & Grey-capped pygmy woodpecker & Dendrocopos canicapillus & 0.423 & 0.373 & 0.331 & 0.485 & 0.154 & 0.577 \\
\hline 14 & Silver-throated bushtit & Aegithalos glaucogularis & 0.628 & 0.253 & 0.427 & 0.655 & 0.228 & 0.573 \\
\hline 15 & Chinese hill warbler & Rhopophilus pekinensis & 0.642 & 0.240 & 0.468 & 0.697 & 0.228 & 0.573 \\
\hline 16 & Common pheasant & Phasianus colchicus & 0.518 & 0.300 & 0.458 & 0.656 & 0.198 & 0.566 \\
\hline 17 & Koklass pheasant & Pucrasia macrolopha & 0.959 & 0.027 & 0.866 & 1.030 & 0.164 & 0.630 \\
\hline 18 & Collared scops owl & Otus lettia & 0.794 & 0.013 & 0.738 & 0.850 & 0.112 & 0.597 \\
\hline 19 & Tawny owl & Strix aluco & 0.808 & 0.033 & 0.699 & 0.968 & 0.269 & 0.545 \\
\hline 20 & Eurasian wren & Troglodytes troglodytes & 0.654 & 0.167 & 0.417 & 0.675 & 0.258 & 0.543 \\
\hline 21 & Willow tit & Poecile montanus & 0.825 & 0.093 & 0.467 & 0.803 & 0.335 & 0.541 \\
\hline 22 & Eurasian jay & Garrulus glandarius & 0.880 & 0.053 & 0.568 & 0.918 & 0.350 & 0.540 \\
\hline 23 & Spotted nutcracker & Nucifraga caryocatactes & 0.826 & 0.040 & 0.583 & 0.891 & 0.308 & 0.536 \\
\hline 24 & Grey-sided thrush & Turdus feae & 0.818 & 0.060 & 0.424 & 0.831 & 0.408 & 0.500 \\
\hline 25 & Crested myna & AcridStraggleres cristatellus & 0.292 & 0.267 & 0.274 & 0.446 & 0.172 & 0.499 \\
\hline 26 & Coal tit & Periparus ater & 0.546 & 0.120 & 0.398 & 0.748 & 0.350 & 0.460 \\
\hline 27 & Little owl & Athene noctua & 0.326 & 0.113 & 0.171 & 0.456 & 0.285 & 0.418 \\
\hline 28 & Chinese thrush & Turdus mupinensis & 0.468 & 0.087 & 0.246 & 0.618 & 0.372 & 0.418 \\
\hline 29 & Eurasian eagle-owl & Bubo bubo & 0.312 & 0.087 & 0.143 & 0.481 & 0.337 & 0.385 \\
\hline 30 & Eurasian treecreeper & Certhia familiaris & 0.474 & 0.027 & 0.235 & 0.713 & 0.478 & 0.359 \\
\hline 31 & Chinese beautiful rosefinch & Carpodacus davidianus & 0.552 & 0.040 & 0.402 & 0.998 & 0.595 & 0.340 \\
\hline 32 & Japanese tit & Parus minor & 0.480 & 0.020 & 0.074 & 0.759 & 0.684 & 0.276 \\
\hline
\end{tabular}


Table A3. Summary of 14 studied resident open-habitat bird species observed from 2008-2017 in Beijing municipality. $B_{s}$ : the weighted mean of open habitat coverage at all site of presence; OF: observation frequency calculated as the number of sites in which a species was observed, divided by the total number of observation sites; LCI: lower limit of $95 \%$ confidence interval for the open habitat coverage at all site of presence; UCL: upper limit of $95 \%$ Confidence Interval for the open habitat coverage at all site of presence; VBCI: variance the open habitat coverage at all site of presence (UCL $-\mathrm{LCL}$ ). Species with both high $B_{S}(>0.3)$ and OF ( $\left.>0.2\right)$ values is the pre-selected candidate focal species (Id 1). Score is calculated as $B_{S} \times 0.3+\mathrm{OF} \times 0.3+(1-\mathrm{VBCI}) \times 0.4$. Species with the highest score were selected as the focal species.

\begin{tabular}{|c|c|c|c|c|c|c|c|c|}
\hline Id & English Name & Scientific Name & $B_{s}$ & OF & LCI & UCI & VBCI & Score \\
\hline 1 & Eurasian collared dove & Streptopelia decaocto & 0.344 & 0.207 & 0.123 & 0.279 & 0.156 & 0.503 \\
\hline 2 & Spotted Dove & Spilopelia chinensis & 0.130 & 0.553 & 0.088 & 0.168 & 0.080 & 0.573 \\
\hline 3 & Common Kestrel & Falco tinnunculus & 0.194 & 0.407 & 0.113 & 0.215 & 0.103 & 0.539 \\
\hline 4 & Eurasian Hoopoe & Upupa epops & 0.203 & 0.327 & 0.113 & 0.227 & 0.114 & 0.513 \\
\hline 5 & Oriental Turtle Dove & Streptopelia orientalis & 0.196 & 0.267 & 0.121 & 0.257 & 0.137 & 0.484 \\
\hline 6 & Hill Pigeon & Columba rupestris & 0.165 & 0.167 & 0.103 & 0.269 & 0.166 & 0.433 \\
\hline 7 & Red-billed Starling & Spodiopsar sericeus & 0.057 & 0.140 & 0.021 & 0.134 & 0.113 & 0.414 \\
\hline 8 & Golden Eagle & Aquila chrysaetos & 0.121 & 0.100 & 0.071 & 0.220 & 0.148 & 0.407 \\
\hline 9 & Daurian Partridge & Perdix dauurica & 0.321 & 0.020 & 0.075 & 0.352 & 0.277 & 0.391 \\
\hline 10 & Asian Short-toed Lark & Calandrella cheleensis & 0.319 & 0.060 & 0.071 & 0.390 & 0.319 & 0.386 \\
\hline 11 & White-bellied Redstart & Hodgsonius phoenicuroides & 0.051 & 0.027 & 0.041 & 0.176 & 0.135 & 0.369 \\
\hline 12 & Long-tailed Shrike & Lanius schach & 0.096 & 0.040 & 0.005 & 0.217 & 0.212 & 0.356 \\
\hline 13 & Chukar Partridge & Alectoris chukar & 0.099 & 0.027 & 0.010 & 0.291 & 0.281 & 0.325 \\
\hline 14 & Crested Lark & Galerida cristata & 0.525 & 0.020 & -0.004 & 0.780 & 0.784 & 0.250 \\
\hline
\end{tabular}


Table A4. Summary of key habitat patches for priority conservation for focal water, forest, and open-habitat bird species in Beijing municipality. Id code refers to the id of the habitat patch. $\mathrm{dPC}$ value represents the contribution of the habitat patch to the overall network connectivity. Key patches with over $50 \%$ area fall into the restricted built-up areas are marked with an asterisk.

\begin{tabular}{|c|c|c|c|c|c|c|c|}
\hline Birds & Id & Patch Name & Area $/ \mathrm{km}^{2}$ & $\mathrm{dPC} / \%$ & Situation in Network & Locatior & $\left(E^{\circ}, N^{\circ}\right)$ \\
\hline \multirow{9}{*}{ Water } & $467 *$ & Chaobai River in Shunyi district & 159.9 & 34.2 & Center of the habitat network & 116.741 & 40.206 \\
\hline & 499 * & $\begin{array}{c}\text { Liangshui \& Xiaotaihou Rivers, wetlands and grass in } \\
\text { Tongzhou district }\end{array}$ & 234.1 & 24.8 & Large patch & 116.729 & 39.807 \\
\hline & $71 *$ & Wenyu and Ba Rivers in Chaoyang district & 122.0 & 18.6 & Large patch and close to key patches 502,503 & 116.605 & 39.990 \\
\hline & 446 & Miyun Reservoir & 205.8 & 18.6 & Large patch & 116.943 & 40.502 \\
\hline & $502 *$ & North Canal and Yunchaojian Rivers in Tongzhou district & 56.3 & 18.3 & Close to large patch 71,499 & 116.717 & 39.908 \\
\hline & $464^{*}$ & Ju and Ru Rivers in Pinggu district & 190.4 & 15.8 & Large patch & 117.038 & 40.129 \\
\hline & 504 * & Sha and Wenyu Rivers in Changping district & 120.5 & 14.7 & Center of the habitat network & 116.348 & 40.115 \\
\hline & $503 *$ & Qing River and Olympic Park in Chaoyang district & 80.4 & 13.6 & $\begin{array}{c}\text { Close to key patch } 71,504 \text { and center of the } \\
\text { habitat network }\end{array}$ & 116.447 & 40.045 \\
\hline & $501 *$ & $\begin{array}{c}\text { Yueya \& Zhongba Rivers and Bojue golf club in Tongzhou } \\
\text { district }\end{array}$ & 22.3 & 12.8 & Close to large patch 71 & 116.714 & 40.000 \\
\hline \multirow{8}{*}{ Forest } & 1 & Mountains in Yanqing, Huairou and Miyun districts & 5289.2 & 86.1 & Large patch & 116.661 & 40.492 \\
\hline & 280 & Mountains in Fangshan and Shijingshan districts & 1821.0 & 39.3 & Large patch & 115.934 & 39.852 \\
\hline & 281 & Mountains in Mentougou district & 1011.7 & 34.8 & Large patch and close to large patch 280,1 & 115.773 & 40.045 \\
\hline & $68^{*}$ & $\begin{array}{c}\text { Forest along the Wenyu River and 6th north ring road in } \\
\text { Shunvi district }\end{array}$ & 62.4 & 1.1 & Center of the habitat network & 116.496 & 40.158 \\
\hline & 244 * & Forest along the Dashi River in Liulihe town & 66.0 & 0.9 & Close to large patch 279 & 116.015 & 39.628 \\
\hline & 127 * & Forest along the Wenyu River in Chaoyang district & 41.7 & 0.7 & Center of the habitat network & 116.574 & 40.018 \\
\hline & 34 & $\begin{array}{c}\text { Forest around Guanting Reservoir and Guishui River in } \\
\text { Yanqing district }\end{array}$ & 35.7 & 0.7 & Close to large patch 1 & 115.854 & 40.429 \\
\hline & 70 * & Forest along the Chaobai River in Shunyi district & 45.3 & 0.6 & Center of the habitat network & 116.698 & 40.129 \\
\hline
\end{tabular}


Table A4. Cont.

\begin{tabular}{|c|c|c|c|c|c|c|c|}
\hline Birds & Id & Patch Name & Area $/ \mathrm{km}^{2}$ & $\mathrm{dPC} / \%$ & Situation in Network & Location & $\left(\mathrm{E}^{\circ}, \mathrm{N}^{\circ}\right)$ \\
\hline \multirow{8}{*}{$\begin{array}{l}\text { Open } \\
\text { habitat }\end{array}$} & 206 & \multirow{2}{*}{$\begin{array}{l}\text { Grass/cropland in Daxing and Tongzhou districts } \\
\text { Grass/cropland in Changping, Shunyi and Huairou } \\
\text { districts }\end{array}$} & 1090.6 & 53.8 & Large patch & 116.575 & 39.693 \\
\hline & 78 * & & 613.0 & 39.8 & Large patch & 116.558 & 40.263 \\
\hline & $324 *$ & \multirow{2}{*}{$\begin{array}{l}\text { Grass/cropland in Shunyi and Pinggu districts } \\
\text { Grass/cropland between Tong zhou, Chaoyang and } \\
\text { Shunyi districts }\end{array}$} & 795.4 & 36.1 & Large patch & 116.953 & 40.189 \\
\hline & $307^{*}$ & & 193.7 & 34.1 & Closed to large patches $206,78,324$ & 116.642 & 40.014 \\
\hline & $310 *$ & Grass/cropland in Fangshan district & 312.5 & 16.5 & \multirow{4}{*}{$\begin{array}{c}\text { Large patch and close to large patch } 206 \\
\text { Large patch } \\
\text { Large patch } \\
\text { Close to large patch } 78 \text { and center of the } \\
\text { habitat network }\end{array}$} & 116.012 & 39.634 \\
\hline & 48 & Grass/cropland around Miyun Reservoir & 222.7 & 9.4 & & 117.025 & 40.543 \\
\hline & 54 & Grass/cropland in Yanqing district & 455.9 & 6.9 & & 116.005 & 40.480 \\
\hline & 319 * & Grass/cropland around Yangfang town & 117.9 & 6.9 & & 116.168 & 40.137 \\
\hline
\end{tabular}




\section{References}

1. United Nations: Department of Economic and Social Affairs. World Urbanization Prospects: The 2018 Revision; United Nations: Department of Economic and Social Affairs: New York, NY, USA, 2018.

2. China Statistical Press. China Statistical Yearbook in 2018; China Statistical Press: Beijing, China, 2018. (In Chinese)

3. Grimm, N.B.; Faeth, S.H.; Golubiewski, N.E.; Redman, C.L.; Wu, J.; Bai, X.; Briggs, J.M. Global Change and the Ecology of Cities. Science 2008, 319, 756-760. [CrossRef]

4. Xun, B.; Yu, D.; Liu, Y.; Hao, R.; Sun, Y. Quantifying isolation effect of urban growth on key ecological areas. Ecol. Eng. 2014, 69, 46-54. [CrossRef]

5. Ortega-Álvarez, R.; MacGregor-Fors, I. Living in the big city: Effects of urban land-use on bird community structure, diversity, and composition. Landsc. Urban Plan. 2009, 90, 189-195. [CrossRef]

6. Canedoli, C.; Orioli, V.; Padoa-Schioppa, E.; Bani, L.; Dondina, O. Temporal Variation of Ecological Factors Affecting Bird Species Richness in Urban and Peri-Urban Forests in a Changing Environment: A Case Study from Milan (Northern Italy). Forests 2017, 8, 507. [CrossRef]

7. Alberti, M. The Effects of Urban Patterns on Ecosystem Function. Int. Reg. Sci. Rev. 2005, 28, 168-192. [CrossRef]

8. Opdam, P.; Steingröver, E.; Rooij, S.V. Ecological networks: A spatial concept for multi-actor planning of sustainable landscapes. Landsc. Urban Plan. 2006, 75, 322-332. [CrossRef]

9. Defries, R.S.; Foley, J.A.; Asner, G.P. Land-use choices: Balancing human needs and ecosystem function. Front. Ecol. Environ. 2004, 2, 249-257. [CrossRef]

10. Wilson, E.; MacArthur, R. The Theory of Island Biogeography; Princeton University Press: Princeton, NJ, USA, 2001.

11. Diamond, J.M. The island dilemma: Lessons of modern biogeographic studies for the design of natural reserves. Biol. Conserv. 1975, 7, 129-146. [CrossRef]

12. Cody, M.L.; Diamond, J.M. Ecology and Evolution of Communities. Nature 1976, 260, 204. [CrossRef]

13. Margules, C.R.; Pressey, R.L. Systematic conservation planning. Nature 2000, 405, 243-253. [CrossRef]

14. Taylor, P.D.; Fahrig, L.; Henein, K.; Merriam, G. Connectivity is a vital element of landscape structure. Oikos 1993, 68, 571-573. [CrossRef]

15. Saura, S.; Pascual-Hortal, L. A new habitat availability index to integrate connectivity in landscape conservation planning: Comparison with existing indices and application to a case study. Landsc. Urban Plan. 2007, 83, 91-103. [CrossRef]

16. Xun, B.; Yu, D.; Wang, X. Prioritizing habitat conservation outside protected areas in rapidly urbanizing landscapes: A patch network approach. Landsc. Urban Plan. 2017, 157, 532-541. [CrossRef]

17. Uezu, A.; Metzger, J.P.; Vielliard, J.M.E. Effects of structural and functional connectivity and patch size on the abundance of seven Atlantic Forest bird species. Biol. Conserv. 2005, 123, 507-519. [CrossRef]

18. Hüse, B.; Szabó, S.; Deák, B.; Tóthmérész, B. Mapping an ecological network of green habitat patches and their role in maintaining urban biodiversity in and around Debrecen city (Eastern Hungary). Land Use Policy 2016, 57, 574-581. [CrossRef]

19. Saura, S.; Rubio, L. A common currency for the different ways in which patches and links can contribute to habitat availability and connectivity in the landscape. Ecography 2010, 33, 523-537. [CrossRef]

20. Pascual-Hortal, L.; Saura, S. Impact of spatial scale on the identification of critical habitat patches for the maintenance of landscape connectivity. Landsc. Urban Plan. 2007, 83, 176-186. [CrossRef]

21. Kang, W.; Minor, E.S.; Park, C.R.; Lee, D. Effects of habitat structure, human disturbance, and habitat connectivity on urban forest bird communities. Urban Ecosyst. 2015, 18, 857-870. [CrossRef]

22. Fajardo, J.; Lessmann, J.; Bonaccorso, E.; Devenish, C.; Muñoz, J. Combined use of systematic conservation planning, species distribution modelling, and connectivity analysis reveals severe conservation gaps in a megadiverse country (Peru). PLoS ONE 2014, 9, e114367. [CrossRef]

23. Gao, Y.; Ma, L.; Liu, J.; Zhuang, Z.; Huang, Q.; Li, M. Constructing Ecological Networks Based on Habitat Quality Assessment: A Case Study of Changzhou, China. Sci. Rep. 2017, 7, 46073. [CrossRef]

24. Dondina, O.; Orioli, V.; Colli, L.; Luppi, M.; Bani, L. Ecological network design from occurrence data by simulating species perception of the landscape. Landsc. Ecol. 2018, 33, 275-287. [CrossRef] 
25. Dondina, O.; Orioli, V.; Chiatante, G.; Alberto, M.; Bani, L. Species Specialization Limits Movement Ability and Shapes Ecological Networks: The Case Study of two Forest Mammals. Curr. Zool. 2018. [CrossRef]

26. Dondina, O.; Saura, S.; Bani, L.; Mateo-Sánchez, M.C. Enhancing connectivity in agroecosystems: Focus on the best existing corridors or on new pathways? Landsc. Ecol. 2018, 33, 1741-1756. [CrossRef]

27. Li, F.; Wang, R.; Paulussen, J.; Liu, X. Comprehensive concept planning of urban greening based on ecological principles: A case study in Beijing, China. Landsc. Urban Plan. 2005, 72, 325-336. [CrossRef]

28. Kong, F.; Yin, H.; Nakagoshi, N.; Zong, Y. Urban green space network development for biodiversity conservation: Identification based on graph theory and gravity modeling. Landsc. Urban Plan. 2010, 95, 16-27. [CrossRef]

29. Dickinson, J.L.; Zuckerberg, B.; Bonter, D.N. Citizen Science as an Ecol. Res. Tool: Challenges and Benefits. Annu. Rev. Ecol. Syst. 2010, 41, 149-172. [CrossRef]

30. Strien, A.J.; Swaay, C.A.M.; Termaat, T.; Devictor, V. Opportunistic citizen science data of animal species produce reliable estimates of distribution trends if analysed with occupancy models. J. Appl. Ecol. 2013, 50, 1450-1458. [CrossRef]

31. Mackenzie, D.I. Occupancy Estimation and Modeling; Elsevier: Amsterdam, The Netherlands, 2006.

32. De Wan, A.A.; Sullivan, P.J.; Lembo, A.J.; Smith, C.R.; Maerz, J.C.; Lassoie, J.P.; Richmond, M.E. Using occupancy models of forest breeding birds to prioritize conservation planning. Biol. Conserv. 2009, 142, 982-991. [CrossRef]

33. Padoa-Schioppa, E.; Baietto, M.; Massa, R.; Bottoni, L. Bird communities as bioindicators: The focal species concept in agricultural landscapes. Ecol. Indic. 2006, 6, 83-93. [CrossRef]

34. Ogden, J.C.; Baldwin, J.D.; Bass, O.L.; Browder, J.A.; Cook, M.I.; Frederick, P.C.; Frezza, P.E.; Galvez, R.A.; Hodgson, A.B.; Meyer, K.D.; et al. Waterbirds as indicators of ecosystem health in the coastal marine habitats of southern Florida: 1. Selection and justification for a suite of indicator species. Ecol. Indic. 2014, 44, 148-163. [CrossRef]

35. Rahman, F.; Ismail, A. Waterbirds: An important bio-indicators of ecosystem. Pertanika J. Schol. Res. Rev. 2018, 4, 81-90.

36. Li, X.; Gong, P.; Liang, L. A 30-year (1984-2013) record of annual urban dynamics of Beijing City derived from Landsat data. Remote Sens. Environ. 2015, 166, 78-90. [CrossRef]

37. Strohbach, M.W.; Lerman, S.B.; Warren, P.S. Are small greening areas enhancing bird diversity? Insights from community-driven greening projects in Boston. Landsc. Urban Plan. 2013, 114, 69-79. [CrossRef]

38. Silva de Araújo, M.L.V.; Bernard, E. Green remnants are hotspots for bat activity in a large Brazilian urban area. Urban Ecosyst. 2016, 19, 287-296. [CrossRef]

39. Fuyuki, A.; Yamaura, Y.; Nakajima, Y.; Ishiyama, N.; Akasaka, T.; Nakamura, F. Pond area and distance from continuous forests affect amphibian egg distributions in urban green spaces: A case study in Sapporo, Japan. Urban For. Urban Green. 2014, 13, 397-402. [CrossRef]

40. Threlfall, C.G.; Walker, K.; Williams, N.S.G.; Hahs, A.K.; Mata, L.; Stork, N.; Livesley, S.J. The conservation value of urban green space habitats for Australian native bee communities. Biol. Conserv. 2015, 187, 240-248. [CrossRef]

41. Luppi, M.; Dondina, O.; Orioli, V.; Bani, L. Local and landscape drivers of butterfly richness and abundance in a human-dominated area. Agric. Ecosyst. Environ. 2018, 254, 138-148. [CrossRef]

42. Hu, W.; Wang, S.; Li, D. Biological conservation security patterns plan in Beijing based on the focal species approach (in Chinese). Acta Ecol. Sin. 2010, 30, 4266-4276.

43. China Bird Report Center. Available online: http:/ / www.birdreport.cn (accessed on 21 December 2017).

44. Li, X.; Liang, L.; Gong, P.; Liu, Y.; Liang, F. Bird watching in China reveals bird distribution changes. Chin. Sci. Bull. 2013, 58, 649-656. [CrossRef]

45. Hamish, W.; Jonathan, B.; Jennifer, S.; Carolina, D.L.R.; Rivadeneira, M.; Walter, J. EltonTraits 1.0: Species-level foraging attributes of the world's birds and mammals. Ecology 2014, 95, 2027. [CrossRef]

46. Brazil, M. Birds of East Asia; Christopher Helm: London, UK, 2009.

47. Lambeck, R.J. Focal Species: A multi-species umbrella for nature conservation. Conserv. Biol. 1997, 11, 849-856. [CrossRef]

48. Bani, L.; Baietto, M.; Bottoni, L.; Massa, R. The use of focal species in designing a habitat network for a lowland area of Lombardy, Italy. Conserv. Biol. 2002, 16, 826-831. [CrossRef] 
49. Hijmans, R.J. Raster: Geographic Data Analysis and Modeling. R Package Version 2.8-19. Available online: https:/ / cran.r-project.org/web/packages/raster/index.html (accessed on 25 March 2017).

50. R Core Team. R: A Language and Environment for Statistical Computing; R Foundation for Statistical Computing: Vienna, Austria, 2015.

51. Huang, C.; Yang, J.; Lu, H.; Huang, H.; Yu, L. Green Spaces as an Indicator of Urban Health: Evaluating Its Changes in 28 Mega-Cities. Remote Sens. 2017, 9, 1266. [CrossRef]

52. Advanced Spaceborne Thermal Emission and Reflection Radiometer Global Digital Elevation Model. Available online: http:/ / reverb.echo.nasa.gov / reverb / (accessed on 27 May 2018).

53. Vector Data of Major Roads. Available online: http://www.bjdata.gov.cn/zyml/ajg/sgtj/5173.htm (accessed on 15 August 2018).

54. Operational Linescan System (OLS) by the U.S. Air Force Defense Meteorological Satellite Program (DMSP)/Version 4 DMSP-OLS Nighttime Lights Time Series. Available online: https://ngdc.noaa.gov/eog/ dmsp/downloadV4composites.html (accessed on 18 August 2018).

55. Land Surface Temperature/Emissivity Monthly L3 Global 0.05Deg CMG. Available online: https:/ / e4ft101. cr.usgs.gov/MOLT/ (accessed on 5 August 2018).

56. European Centre for Medium-Range Weather Forecasts (ECMWF) ERA-Interim, Monthly means of Daily Forecast Accumulations. Available online: http://apps.ecmwf.int/datasets/data/interim-mdfa/levtype= sfc/ (accessed on 6 August 2018).

57. Huang, Y.; Zhao, Y.; Li, S.; von Gadow, K. The Effects of habitat area, vegetation structure and insect richness on breeding bird populations in Beijing urban parks. Urban For. Urban Green. 2015, 14, 1027-1039. [CrossRef]

58. McGarigal, K.; Cushman, S.A.; Ene, E. FRAGSTATS v4: Spatial Pattern Analysis Program for Categorical Maps; Computer software program produced by the authors at the University of Massachusetts: Amherst, MA, USA, 2012; Available online: http:/ / www.umass.edu/landeco/research/fragstats/fragstats.html (accessed on 13 April 2017).

59. Li, X.; Si, Y.; Ji, L.; Gong, P. Dynamic response of East Asian Greater White-fronted Geese to changes of environment during migration: Use of multi-temporal species distribution model. Ecol. Model. 2017, 360, 70-79. [CrossRef]

60. Rosin, Z.M.; Piotr, S.; Paweł, S.; Marcin, T.; Andrzej, L.; Piotr, T. Constant and seasonal drivers of bird communities in a wind farm: Implications for conservation. PeerJ 2016, 4, e2105. [CrossRef]

61. Summers, P.D.; Cunnington, G.M.; Fahrig, L. Are the negative effects of roads on breeding birds caused by traffic noise? J. Appl. Ecol. 2011, 48, 1527-1534. [CrossRef]

62. Orłowski, G. Roadside hedgerows and trees as factors increasing road mortality of birds: Implications for management of roadside vegetation in rural landscapes. Landsc. Urban Plan. 2008, 86, 153-161. [CrossRef]

63. Ghosh, T.; Anderson, S.J.; Elvidge, C.D.; Sutton, P.C. Using nighttime satellite imagery as a proxy measure of human well-being. Sustainability 2013, 5, 4988-5019. [CrossRef]

64. Strittholt, J.R.; Dellasala, D.A. Importance of Roadless Areas in Biodiversity Conservation in Forested Ecosystems: Case Study of the Klamath-Siskiyou Ecoregion of the United States. Conserv. Biol. 2001, 15, 1742-1754. [CrossRef]

65. Dormann, C.F.; Elith, J.; Bacher, S.; Buchmann, C.; Carl, G.; Carré, G.; Marquéz, J.R.G.; Gruber, B.; Lafourcade, B.; Leitão, P.J.; et al. Collinearity: A review of methods to deal with it and a simulation study evaluating their performance. Ecography 2013, 36, 27-46. [CrossRef]

66. ESRI. ArcGIS Desktop: Release 10.3.1; Environmental Systems Research Institute: Redlands, CA, USA, 2015.

67. Fiske, I.J.; Chandler, R.B. Unmarked: An R package for fitting hierarchical models of wildlife occurrence and abundance. J. Stat. Softw. 2011, 43, 1-23. [CrossRef]

68. Bartoń, K. MuMIn: Multi-Model Inference; R Package Version 1.42.1; Available online: https:/ / cran.rstudio. com/web/packages/MuMIn/ (accessed on 23 November 2017).

69. Burnham, K.P.; Anderson, D.R. Model Selection and Multimodel Inference: A Practical Information-Theoretic Approach, 2nd ed.; Springer: New York, NY, USA, 2002.

70. MacKenzie, D.I.; Bailey, L.L. Assessing the fit of site-occupancy models. J. Agric. Biol. Environ. Stat. 2004, 9, 300-318. [CrossRef]

71. Symonds, M.R.E.; Moussalli, A. A brief guide to model selection, multimodel inference and model averaging in behavioural ecology using Akaike's information criterion. Behav. Ecol. Sociobiol. 2011, 65, 13-21. [CrossRef] 
72. Liu, C.; Berry, P.M.; Dawson, T.P.; Richard, G. Pearson Selecting thresholds of occurrence in the prediction of species distributions. Ecography 2005, 28, 385-393. [CrossRef]

73. Saura, S.; Torné, J. Conefor Sensinode 2.2: A software package for quantifying the importance of habitat patches for landscape connectivity. Environ. Model. Softw. 2009, 24, 135-139. [CrossRef]

74. Jenks, G.F. The Data Model Concept in Statistical Mapping. Int. Yearb. Cartogr. 1967, 7, 186-190.

75. Shimazaki, H.; Tamura, M.; Darman, Y.; Andronov, V.; Parilov, M.P.; Nagendran, M.; Higuchi, H. Network analysis of potential migration routes for Oriental White Storks (Ciconia boyciana). Ecol. Res. 2004, 19, 683-698. [CrossRef]

76. Saura, S.; Bodin, Ö.; Fortin, M.-J. Editor's choice: Stepping stones are crucial for species' long-distance dispersal and range expansion through habitat networks. J. Appl. Ecol. 2014, 51, 171-182. [CrossRef]

77. Li, X.; Wang, Y. Applying various algorithms for species distribution modelling. Integr. Zool. 2013, 8, 124-135. [CrossRef]

78. Tiwary, N.K.; Urfi, A.J. Spatial variations of bird occupancy in Delhi: The significance of woodland habitat patches in urban centres. Urban For. Urban Green. 2016, 20, 338-347. [CrossRef]

79. Merken, R.; Deboelpaep, E.; Teunen, J.; Saura, S.; Koedam, N. Wetland Suitability and Connectivity for Trans-Saharan Migratory Waterbirds. PLoS ONE 2015, 10, e0135445. [CrossRef]

(C) 2019 by the authors. Licensee MDPI, Basel, Switzerland. This article is an open access article distributed under the terms and conditions of the Creative Commons Attribution (CC BY) license (http://creativecommons.org/licenses/by/4.0/). 